\title{
Makeni City Council and the Politics of Co-production in Post-conflict Sierra Leone
}

\author{
Anna Workman*
}

Abstract Policymakers in Sierra Leone have identified recently established local councils as the main vehicles for delivering on commitments to improve local public goods provision, but little is known about which strategies work for councils as public goods providers, and why. I compare two cases of public goods provision led by a single urban council, one relatively successful, another less so. I find that both are examples of co-production of public goods by the council and interest-based associations and that the dynamics of the relationships between these actors strongly influence the quality of public goods outcomes. I argue that the presence of a pattern of reciprocal exchange is the most significant determinant of success in co-production. I conclude by considering the conditions under which reciprocity is most likely to emerge in the context of co-productive relationships between local councils and interest-based associations.

\section{Introduction}

In the aftermath of a decade of civil war in Sierra Leone (1991-2002), indicators of wellbeing linger close to the bottom of comparative league tables (UNDP 2009). Better local public goods ${ }^{1}$ provision is widely recognised as critical to improving the quality of life and maintaining political stability. The Sierra Leone government and international donors have pinned high expectations on recently established local councils to improve the quality and availability of local public goods (Government of Sierra Leone 2008; World Bank 2009b). However, there has been very little empirical research which investigates how local councils have provided public goods to date, the political challenges they have encountered, or the relative successes of the different approaches they have adopted. This article addresses that gap in knowledge.

The rapid decentralisation of power in Sierra Leone in 2003-04 was legitimised by an emerging narrative about the causes of the civil war which characterised the centralised state's exclusion of the majority of Sierra Leoneans from the political process and its failure to provide local public goods as drivers of violent dissent (Sierra Leone Truth and Reconciliation
Commission 2004). Following the passage of the Local Government Act (LGA) in March 2004 and subsequent local elections in May 2004, 19 local councils took office, of which five were urban councils. The LGA outlined a programme of political and fiscal decentralisation, according councils overall responsibility for development in their localities; devolving a range of ministerial functions related to basic public goods provision; and empowering councils to tax and spend within certain parameters.

In this article, I investigate why some instances of public goods provision led by local councils in Sierra Leone succeed, while others fail. I do so through comparison of two cases of public goods provision ${ }^{2}$ led by a single urban council, Makeni City Council (MCG). ${ }^{3}$ The first, a clean market, is relatively successful, and the second, a safe supply of meat, is less so. Both of these cases happen to be examples of co-production of public goods by MCC and members of interest-based associations. ${ }^{4}$ I adopt Joshi and Moore's definition of co-production as 'the provision of public services... through a regular long-term relationship between state agencies and organized groups of citizens, where both make substantial resource contributions' (Joshi and

IDS Bulletin Volume 42 Number 2 March 2011 @ 2011 The Author. IDS Bulletin @ 2011 Institute of Development Studies Published by Blackwell Publishing Ltd, 9600 Garsington Road, Oxford OX4 2DQ, UK and 350 Main Street, Malden, MA 02148, USA 
Moore 2004: 31), substituting public goods for public services. As they point out, many hybrid arrangements captured by the concept of coproduction remain invisible to development policymakers because they do not fit within the standard repertoire of accepted models for public goods provision. While inter-organisational partnership is now widely recognised as one strategy for providing public goods, the focus is usually on contractual relationships between government agencies and either private businesses or NGOs. Co-productive relationships between local councils and interest-based associations are often more fluid in character, relying on continuous negotiation rather than contract, and can also be intensely political.

I argue that successful co-production by local councils and interest-based associations in Sierra Leone relies on establishing and sustaining a pattern of reciprocal exchange. I develop three hypotheses about the conditions under which reciprocal exchange between local councils and interest-based associations in Sierra Leone is likely to occur, and co-production succeed:

(1) both parties recognise their mutual need or dependence; (2) the structure according to which co-productive inputs are made allows immediate sanction for failures of reciprocity, or a third party enforces the parties' commitments; and (3) local councils can take advantage of existing regulatory mechanisms to reduce free-riding ${ }^{5}$ by members of interest-based associations.

This article proceeds as follows. In Section 2, I introduce the two cases of co-production led by MCG and consider first-level explanations for their differing degrees of success. In Sections 3 and 4, I analyse the deeper incentives/deterrents which shape the choices made by MCC and members of interest-based associations in the context of these co-productive arrangements. In Section 5, I conclude by presenting three hypotheses about the conditions under which successful co-production by local councils and interest-based associations is likely to occur in Sierra Leone.

\section{Two cases of co-production of public goods}

The city of Makeni is the provincial headquarters of northern Sierra Leone with a population of approximately 83,000 (Statistics Sierra Leone 2004) and a stronghold of support for the All People's Congress (APG) party which came into power in 2007. When I arrived in Makeni in early 2009, I collected data about potential cases of public goods provision led by Makeni City Council (MCG) through a two-step process: (1) preliminary interviews with local councillors; and (2) a survey of senior representatives of households $(n=279) .{ }^{6}$ Through this process, I identified a clean central market as a relatively successful instance of public goods provision and a safe supply of meat from the city's slaughterhouse as a relatively unsuccessful one. Further data collected about each case through a combination of participant observation, semistructured interviews and document review were consistent with this characterisation of the cases.

The market is cleaned by MCG in cooperation with the traders, who are represented by the Makeni branch of the Sierra Leone Traders' Union, known locally as the Traders' Union (TU). MCC collects waste, using its only rubbish truck to ply the narrow street which runs through the market and one or two motorised tricycles to collect waste from the market's periphery. The frequency with which waste is collected in the market fluctuates depending on the availability of vehicles and fuel, dropping from daily to thrice weekly between May and August 2009, but a minimum flow of resources is always maintained by MCG so that waste collection can continue. MCG is heavily reliant on traders to help gather waste for collection. Traders sweep their own areas and prepare neat piles of waste for pick-up; pay young men to serve as sweepers inside the congested market buildings; and dig out clogged gutters and clear piles of standing waste on periodic city-wide cleaning days. They also pay daily dues of Le200 (£0.04) $)^{7}$ per table or annual licence fees which usually fall between Le50,000-100,000 (£9.50-£19.00) to MCG, which is used to supplement the central government grant for waste collection. Free-riding by refusing to contribute labour or money to the cleaning effort appears to be low, and the TU remains open to negotiation about the rates charged for dues and licence fees.

MCC also cooperates with the butchers, represented by the Butchers' Association (BA), to carry out supervised slaughtering of cattle at Makeni's slaughterhouse. When the slaughterhouse was constructed in late 2004, it seemed an impressive achievement - a spacious building with generator-provided electricity, 
freezers and running water. ${ }^{8}$ Following negotiations with MCG in early 2005, the butchers agreed to pay a slaughtering fee of Le4,000 (£0.76) per cow and an annual fee of Le50,000 (£9.50) per meat stall to contribute towards the costs of running the slaughterhouse. By June 2009, the slaughterhouse had fallen into a state of disrepair, the generator had broken down and not been repaired, and the only water source available was a small stream that ran behind the building. Makeni's 11 registered butchers, or more commonly their assistants, bring their cattle to the slaughterhouse before dawn each day, often travelling quite long distances on foot in the darkness. By the light of homemade kerosene lamps, they slaughter their cattle and MCG's environmental health officer (EHO) inspects the meat, holding back any parts he believes unsafe for consumption. Non-attendance at the slaughterhouse can be considered a form of freeriding because those butchers who slaughter elsewhere benefit from information about outbreaks of cattle disease without contributing towards the costs of surveillance. One butcher is known to routinely slaughter outside of the slaughterhouse, while one-third of the butchers and assistants interviewed said they had slaughtered a cow outside the slaughterhouse at least once since its construction. According to the EHO, the last time MCC's chief administrator (CA) tried to negotiate an increase in the slaughtering fee with the chairman of the BA, he was angrily rebuffed because the butchers felt that they were paying for facilities such as electricity and water, which were no longer being provided.

I observed three important, inter-linked differences between these two cases of coproduction of public goods, which serve as firstlevel explanations for the performance gap between them:

- Resources. In both cases, the consistency and quality of MCG's inputs are affected by constrained resource flows. Waste collection suffers from an uneven flow of resources, which means that the level of service fluctuates. The slaughterhouse is being steadily starved of resources, which means that the level of service continually declines.

- Prioritisation. Both the mayor and the CA informed me that MCG had decided to concentrate on waste collection as its highest priority. While the decision to prioritise waste collection is not a formal one, documented in MCC's annual development plan, it is explicit. MCG's commitment to waste collection is demonstrated by the mayor's personal involvement in monitoring this activity and the presence of ongoing resources to fund it. Evidence of the implicit decision to neglect the slaughterhouse is provided by MCG's persistent failure to act on warnings from workers and councillors about the problems occurring there.

- Cooperation of interest-based associations. The presence of inputs by members of co-producing interest-based associations is essential to the provision of a clean market and a safe supply of meat. Free-riding by butchers appears to present a greater threat to meat safety than free-riding by traders does to market cleanliness because the small size of the butchers as a group means that the impact of every free-rider is felt and non-attendance at the slaughterhouse directly introduces uninspected meat into the supply, while freeriding through avoiding cleaning or paying dues merely shifts a larger burden of work or higher cost onto those that participate. At the executive level, the relationship between MCG and the BA has reached an impasse because of the BA's refusal to pay higher fees, while MCC and the TU continue to negotiate over dues.

These first-level explanations lead to two further questions: (1) Why did MCC decide to prioritise waste collection in the market, and back that decision with resources? (2) Why are the TU and its members more willing to cooperate with MCG than the BA and its members? I will address these questions in Sections 3 and 4, respectively.

\section{Incentives/deterrents for MCC 3.1 External funding}

Resource scarcity is one of the defining characteristics of the broader sociopolitical environment in which MCG operates. The council survives predominantly on a range of modest grants from central government, which are backed by donor funding and 'tied' to specific categories of expenditure. According to MCG's 2008 financial statement, ${ }^{9}$ these grants amounted to approximately Le647 million $(£ 122,900)$ in 2008, making up 65 per cent of MCG's total recorded income of approximately Le996 million (£189,200), while own source revenue accounted 
for only 34 per cent. In this context of overall deprivation, one of the most powerful incentives influencing MCC decision-making is access to external funding. ${ }^{10}$ Senior MCG staff members are understandably reticent to identify money as a motivation for their actions, but there is substantial circumstantial evidence to suggest that MCG prioritises waste collection and neglects the slaughterhouse because of the relative financial gain to be had from each.

MCG receives regular injections of resources to support waste collection in the form of a quarterly 'tied' grant for solid waste management (recorded as an annual total of approximately Le45 million (£8,500) in 2008) and ongoing donations of vehicles and other equipment from foreign governments and international organisations. More temptingly, waste collection has the potential to attract large-scale cash grants which MCG could manage itself, creating opportunities for diversion of a portion of the funds. In 2009, the mayor was alerted that over $£ 250,000$ in World Bank funds was available for landfill sites in four cities and would be allocated on a first-come, first-served basis. If MCG secured a quarter of this collective fund, the amount received would be equivalent to approximately 30 per cent of its annual reported income in 2008 - a substantial prize.

Since its completion, the slaughterhouse has offered very weak opportunities for financial reward. It is very likely that some portion of the original slaughterhouse budget of approximately Le97 million $(£ 18,400)^{11}$ was returned to MCC staff and political representatives in the form of a kickback from the construction contractor, as this practice is widely considered to be routine. The total reported income from the slaughterhouse in 2008 was approximately Le4.3 million (£820), which was not even sufficient to cover the costs of frontline workers and the supply of kerosene. From the time the slaughterhouse was completed, there has been next to no external interest in the facility, and neither money nor equipment has been forthcoming. MCG has not made any attempt to fundraise for the slaughterhouse, perhaps recognising its relative lack of saleability to donors.

When MCG receives external funding to support waste management, it comes under pressure to demonstrate a minimum level of results in order to keep the money flowing. This leads MCG to become more dependent on the traders, as the co-productive relationship between MCG and the traders provides a low-cost means to demonstrate results in one of the city's most visible locations - the market. At the same time, MCG has adequate resources to make sustained contributions to the cleaning effort. Without regular injections of external resources, MCC lacks the capacity and the motivation to invest in the upkeep of the slaughterhouse and allows the facility to deteriorate.

\subsection{Political capital}

MCG's decision to prioritise waste collection in the market can also be explained by its desire to acquire political capital with the traders, who make up one of the most powerful economic blocs in the city. According to MCG records, market dues from those trading at tables totalled approximately Le139 million (£26,400) in 2008, 14 per cent of MCG's total recorded income and 42 per cent of MCG's own source revenue. Aside from the valuable income they provide for the city, the traders have a proven capacity to disrupt MCG. This was demonstrated during a period of mounting tension between the TU and the postreform MCG, which began shortly after the 2004 local elections and culminated in the forced resignation of the first MCC chairman ${ }^{12}$ in early 2006. I now briefly describe the main events of this conflict in order to illustrate the character of the relationship between MCG and the TU.

Following the May 2004 local elections, MCG privatised dues collection in the market, awarding the contract to the Dollar Guys, an association of money changers, rather than the TU. Angered by this decision, the TU's executive was primed to organise against the MCG chairman when a corruption scandal broke against him in late 2005 over the misuse of MCG's 2005 Local Government Development Grant. In January 2006, the MCG chairman ignored the efforts of his own party, the APC, to force his resignation, and turned towards the ruling Sierra Leone People's Party (SLPP) for support (Anonymous 2006a). In February 2006, the city's frustrated residents, including the traders, engaged in a full-day strike. The SLPP government's resident minister for the northern region immediately joined calls for the chairman to stand down, leading to his resignation two days later (Anonymous 2006b,c). The participation of the traders was essential to the success of the 
strike because of their ability to shut down economic activity in the city and withdraw one of MCC's most critical sources of income.

The TU's struggles with MCG did not end with the introduction of a new chairman, but rather entered a new cycle. The TU was finally awarded the contract for dues collection in the market in 2006, but quickly fell behind with its payments, and came under suspicion of corruption itself. The TU's efforts to withdraw from its contract for dues collection with MCG were unsuccessful, and by December 2007, the TU's debt had reached almost Le 13 million (£2,400). The July 2008 elections saw the introduction of a new mayor, the third post-reform change in the political leadership of MCG. The contract for dues collection in the market once again returned to the Dollar Guys. While initially MCG seemed set to pursue an aggressive strategy against the TU to recover its debt, proposing the possibility of court action, later on the matter was quietly dropped. The CA told me, 'We need an improved personal relationship. For a traditional Temne man, once you take him to court, he is an enemy for life'. This was in many ways a shrewd move, which went some way to mend fences, but left MCC with leverage over the TU.

In the context of the détente under way between MCG and the TU, MCC's decision to prioritise cleaning of the market can be viewed as a way to build political capital with the traders and encourage improving relations. The traders constitute a significant source of MCC revenue and a substantial body of political support (or opposition). By performing well in waste collection, MCG can acquire political capital to spend in securing a share of the important economic and political resources controlled by the traders. In 2009, MCC was arguably already using political capital acquired through regular waste collection to negotiate an increase in market dues. The desire to acquire political capital with the traders is a rather fragile incentive for MCG action, dependent on the variable quality of MCG's conflict-prone relationship with the TU.

Relations between MCC and the BA have a far more detached character. When I spoke to the chairman of the BA in June 2009, he told me that he had not met with the mayor at any point during his first year in office to discuss the slaughterhouse. The butchers make only a small contribution to MCG revenue: their slaughtering fees brought in less than 1 per cent of total recorded income in 2008. While one-half of the butchers and assistants interviewed were born in Bombali Sebora chiefdom, two-thirds of them identify as Fula, rather than Temne (the ethnic majority). The local reputation of this minority ethnic group is that they are careful to avoid political controversy. One Fula butcher described this cautious approach as the best way to protect one's property, saying, 'You have a vehicle, children, a wife, a business... If you have conflict, you might lose one of those things'.

Historian Alusine Jalloh (1999) argues that throughout the post-independence period, Fulas have favoured a pragmatic approach to involvement in politics which consists of prioritising their business interests and adapting to changing configurations of power, rather than seeking to shape them. Jalloh finds that despite this business-oriented approach, Fulas suffered as a result of the transition from SLPP to APG rule in $1967-8 .{ }^{13}$ During 16 years of SLPP rule (1951-67), Fula merchants developed a close relationship to the SLPP leadership, making substantial financial contributions to the SLPP between 1961-7 and supporting the party in the 1967 elections. Their refusal to provide similar support for Siaka Stevens' 1967 APC campaign led to the harassment of Fulas during the elections and their subsequent alienation from the APG government. Fula attempts to negotiate a better relationship with Stevens' APC government were set back after Stevens illegally deported Freetown's Fula chief Alhaji Bah in 1971 to face imprisonment in Guinea at the will of his ally President Touré. In 1975, after extensive Fula lobbying, he was eventually released and restored to his earlier position. Despite his poor treatment at the hands of the APC, in 1978 Alhaji Bah led a sustained Fula mobilisation to secure protection for Fula business interests in exchange for financial contributions to the APC. This troubled political history provides further justification for a contemporary strategy of caution.

Further investigation into the political history of Fulas in Makeni is needed for a fuller understanding of the political dynamics of the relationship between the predominantly Fula butchers and MCC. However, it seems reasonable to draw a preliminary conclusion that the Fula butchers' cautious profile prevents 
MCG from fearing disruptive action organised by the butchers. Given this, the BA's related passivity, and the limited revenue that the butchers bring in for MCC, it is not surprising that MCG sees little incentive to acquire political capital with the butchers through exerting itself at the slaughterhouse.

\section{Incentives/deterrents for members of interest based associations \\ 4.1 Reciprocity}

One of the main challenges to cooperation between MCG and members of interest-based associations is the poor legacy of local government in Makeni, which is characterised by repeated cycles of corruption and betrayal. Bolten argues that the people of Makeni operate according to a 'conflicted narrative of governance', caught between 'hope and cynicism' (Bolten 2008: 84). The very existence of co-productive relationships for public goods provision can be viewed as an expression of hope by members of interest-based associations. They reflect a desire for better conditions in their places of work and a willingness to cooperate with government in order to achieve them. However, cynicism prevents members of interest-based associations from contributing freely to public goods provision without direct evidence of government reciprocity.

Positive reciprocity can be defined as 'the giving of benefits to another in return for benefits received' (Molm et al. 2007: 199). Molm and her colleagues argue that acts of positive reciprocity convey two distinct dimensions of value to the recipient: instrumental and symbolic. On a symbolic level, acts of positive reciprocity build trust and communicate appreciation for benefits received. According to this theory, positive reciprocal behaviour by MCC has the potential to motivate members of interest-based associations to contribute to public goods provision, and to develop trust and positive regard between them. However, reciprocity can also be negative - either party can punish the other for denying them benefits or behaving unfairly - communicating disregard and eroding trust.

In general, traders are more willing to contribute to the cleaning of the market than butchers are to the operations of the slaughterhouse because MCG reciprocates their efforts. There is no formal contract which lays out the inputs that MCG and the traders will make to the cleaning effort. The co-productive relationship works through frequent reciprocal exchange - the traders gather waste and MCG collects it. If MCG fails in its obligations to collect waste, the traders can reduce or cease their efforts to gather it, acting individually or collectively. Traders do not consistently impose sanctions against MCC for poor performance, but they have done so in some instances. Bolten (2008) describes just such an episode of negative reciprocity in mid-1996, when Makeni's residents heaped up rubbish at the market and on main roads to protest the lack of waste collection. This model of daily reciprocal exchange on which cleaning of the market is based works well because the traders do not feel vulnerable to being taken advantage of by MCC. They have accurate information about whether MCG is collecting waste and a range of graduated responses at their disposal, whether or not they choose to invoke them every time that MCG performs poorly.

The butchers agreed to pay a slaughtering fee of Le4,000 (£0.76) per cow and an annual fee of Le50,000 (£9.50) per meat stall on the understanding that MCG would provide a fully staffed slaughterhouse facility with running water, electricity and a refrigerator. While this agreement requires an element of daily exchange, it also demands that MCG makes longer-term investments to maintain the building and equipment. It was difficult for the butchers to monitor whether MCG was investing sufficiently in maintenance at first, but MCC's persistent failure to fix the damaged water pipes or the broken generator sent a clear message that they would not fulfil their agreed commitments. The BA chairman describes this breakdown of reciprocity:

They built the slaughterhouse, brought water, made all the facilities, gave them to us, they even bought us a freezer, but that was all for one month, two months... After that, nothing. They gave us electric light there, in the mornings when we go to slaughter, but right now nothing... That is finished. But any cow that we kill over there, we pay Le4,000 per cow, we are paying for the council, the city.

The BA chairman's refusal to renegotiate the slaughtering fee upward and the refusal of some butchers to consistently slaughter at the slaughterhouse can be interpreted as acts of negative reciprocity. 


\subsection{Regulation}

Regulation through a system of rules and sanctions is a widely recognised strategy for reducing free-riding behaviour by making it more costly. Ostrom defines rules as 'shared understandings by participants about enforced prescriptions concerning what actions (or outcomes) are required, prohibited or permitted' (Ostrom 2005: 18). This definition includes working rules derived from any source, whether formal or informal. MCG faces two significant challenges in regulating the traders and the butchers to coerce them into behaving cooperatively. First, MCC rules applying to cleaning the market and producing safe meat are rather fuzzy, derived from a mixture of older legislation, established practice and recent decisions within council meetings. The Local Government Act empowers MCG to create its own by-laws, but MCC had not yet done so by September 2009. Second, MCG has limited staff available to carry out monitoring and enforcement activities. MCG rules regarding cleaning of the market and slaughtering of meat are therefore weakly enforced, usually through intermittent imposition of sanctions. MCG is more likely to catch extreme violations, such as an attack on the rubbish truck, than routine ones, such as low daily effort in gathering waste for collection.

In the market, however, there are regulatory systems operating independently of MCC, which help to encourage cooperative behaviour regarding cleaning. First, there are three market chiefs who resolve disputes between traders and act as monitors and trouble-shooters. The market chiefs are approved by the paramount chief and act under his authority, but they are also executive members of the TU. They do not perceive themselves to have any specific responsibility for market cleaning, but on citywide cleaning days, they can be seen walking up and down the narrow street through the market, overseeing traders' efforts and offering encouragement. In this way, they create a certain pressure to cooperate with the cleaning effort.

Second, traders regulate each other through normative pressure. Traders are highly visible to one another - they sell their goods in the same spaces every day and belong to subgroups of the TU such as the Cigarette Sellers' Association, each with its own chairperson. They are not only each other's neighbours, but each other's creditors, lending money or goods when needed. If a trader does not follow rules such as sweeping his or her area, or contributing for additional sweepers, s/he is likely to be sanctioned by social disapproval which could damage his or her reputation and interrupt his or her access to intra-group benefits. Conversations with traders suggest that expressions of social disapproval are usually quite mild, but for those highly dependent on their peers, even a mild rebuke can have a powerful influence.

Third, members of the TU executive can regulate traders' behaviour by withdrawing their access to trading space. The TU chairman described threatening to seize the tables of those who did not clean their own areas prior to his dispute with MCG. However, the TU executive is likely to be supportive of MCC's aims only when the two bodies are aligned.

Butchers, like other traders, are highly dependent on each other for periodic loans. Their business is capital intensive because of the high cost of purchasing a single cow. It is common for butchers to purchase a cow on a repayment basis from another butcher or a cattle trader, or to pair up and take turns slaughtering a cow and sharing out the meat to prevent having to freeze too much overnight. Butchers are therefore well positioned to apply normative pressure on one another to attend the slaughterhouse, but appear not to do so. Perhaps this can be explained by the fact that nonattendance of one butcher at the slaughterhouse does not immediately create extra work for another butcher. It does, however, leave the burden of payment on those attending the slaughterhouse, and may in the future lead to steeper rises in slaughtering fees due to a narrower base of fee-payers. Alternatively, butchers' dissatisfaction with the slaughterhouse may make them sympathetic to free-riding as an act of negative reciprocity.

The BA chairman does advocate to local government on behalf of the butchers, but he is far less active than the TU executive in this regard. The BA's main function seems to be coordinating mutual support efforts to keep each butcher operating at a profit. According to the BA chairman, meetings of the butchers focus mainly on current threats to profitability and the 
BA collects contributions to support any butcher who sustains a shock to his business. The BA chairman has passed responsibility for most of the daily running of his butcher business onto his sons, and appears to serve more as a senior adviser for a group of businessmen than a regulator. Individual butchers' choices not to attend the slaughterhouse seem to go relatively unchallenged by him. Therefore even selfregulation by the butchers' own association is weak, compared to that of the traders.

\section{Conclusions}

What can comparison of these two cases tell us about why some instances of public goods provision led by local councils in Sierra Leone succeed, while others fail? My analysis suggests that when local public goods are provided through co-production by local councils and interest-based associations, the dynamics of the co-productive relationship are a critical determinant of the quality of public goods provision. Successful coproduction appears to rely on establishing and sustaining a pattern of reciprocal exchange between the parties. Given the political context in Sierra Leone, I propose three broader hypotheses about the conditions under which a pattern of reciprocal exchange between local councils and interest-based associations might be sustained, and co-production succeed.

First, co-production is more likely to succeed when both parties recognise their mutual need or dependence. In the cases I describe, recognition of mutual dependence is made more complicated by the fact that MCG appears not to value public goods for their own sake, but rather for the economic or political resources that can be secured through their provision. Although MCG cannot ensure the safety of the meat supply without the butchers' cooperation, MCG's relative indifference to achieving this outcome means that these are insufficient grounds for it to recognise its dependence on the butchers. The butchers offer little in the way of revenue or political clout to serve as an alternate basis for MCG dependence. By contrast, MCG recognises its dependence on the traders on three counts: working with the traders provides a low-cost means to demonstrate visible results of waste collection to donors and central government; market dues paid by traders constitute a significant source of revenue; and the traders' political support enables MCG to negotiate increases in dues and forestall disruptive action. It is the traders' control of important economic and political resources that facilitates the emergence of a pattern of positive reciprocity with MCG.

Many traders value having a clean market, which makes it relatively straightforward for them to recognise their dependence on MCG as a waste collector. The butchers seem to have more ambiguous feelings about the importance of supervised slaughtering as a means to ensuring the safety of the meat supply. When critical resources such as electricity, water and a freezer are taken away, some do not sufficiently value the slaughterhouse to recognise their dependence on MCG, and choose to free-ride. If MCG were to make a concerted effort to improve the slaughterhouse, it would need to address these motivational challenges as well as increase the flow of resources to the facility.

Second, given low levels of trust, co-production is more likely to succeed when the structure according to which co-productive inputs are made allows immediate sanction for failures of reciprocity, or when a third party enforces coproducing parties' commitments. The ease with which MCG and the traders can sanction one another by ceasing to contribute to the cleaning effort gives rise to commitments on both sides which are, in a sense, self-enforcing. In contrast, MCG did not suffer any sanction when it failed to uphold its commitments to the butchers. This is indicative of weak bottom-up and top-down oversight of MCG as a public goods provider. The domination of a single political party which handpicks candidates and weak 'community' monitoring of public goods provision leave MCG relatively unaccountable to Makeni's residents. Top-down oversight of MCC is provided by a range of actors within the finance and local government ministries, ${ }^{14}$ but to my knowledge, none of these actors routinely reward or punish performance in public goods provision. ${ }^{15}$ David Booth (see Booth, 'Towards a Theory...', this IDS Bulletin) identifies the presence of 'corporate performance disciplines' in provider organisations as one of three key conditions associated with better public goods provision by African local governments, arguing that such performance disciplines can be effective 'even when... the sociopolitical context and professional norms retain important patrimonial 
or clientelistic features'. In the case of the slaughterhouse, top-down pressure could have been created by introducing a senior government official as a third party enforcer to witness the agreement between $\mathrm{MC}$ and the butchers and impose sanctions if commitments were not upheld, which might have helped sustain reciprocal behaviour. The involvement of a third party enforcer need not preclude regular renegotiation of parties' commitments to one another to maintain flexibility.

Third, co-production is more likely to succeed when local councils can take advantage of existing regulatory mechanisms to reduce freeriding by members of interest-based associations. Traders in Makeni's market (including market chiefs and executive members of the TU) demonstrate a capacity for and interest in selfregulation regarding waste collection, while butchers show little interest in enforcing slaughtering requirements. It seems likely that other councils will face the same challenges as MCG in addressing free-riding or destructive behaviour by members of interest-based associations: the lack of a clear legal/regulatory framework and insufficient resources for monitoring and enforcement activities. Councils may wish to invest in improving their capacity in this regard, but they can also make use of other regulatory machinery where it is available. In doing so, they are incorporating 'institutional elements inherited from the past' which are 'problem-solving' in the relevant context (see Booth, 'Introduction', this IDS Bulletin). Citing Avner Greif (2006), Booth suggests that institutional elements from the past are important to public goods provision because they serve as low-cost, default templates for action, enabling actors to avoid the high costs and collective action problems involved in creating new institutions.

Both chieftaincy and associational structures may offer helpful regulatory machinery for councils. The network of local sub-chiefs in Sierra Leone is extensive and their main function is the maintenance of public order. However, in taking advantage of chiefs' regulatory capacity, councils could run the risk of enabling chiefly abuses of power, which some argue were a significant driver of conflict (Hanlon 2005; Richards 2005).

Tensions between councils and chiefs in some areas also undermine possibilities for cooperation. The potential of chiefs to serve as supplementary regulators needs to be assessed in the context of the locale and public good in question. Exploitative behaviour by chiefs is likely to be lower in urban areas where competitive pressure from other government actors and exposure to public scrutiny impose certain limits. Within interest-based associations, both peers and executive members can serve as regulators. Leonard's work on veterinary associations in Africa suggests that informal self-regulation among peers which makes opportunities for profitable collaboration contingent on adherence to certain standards is likely to be more achievable than formal self-regulation based on a system of sanctions because it is usually difficult to find a subgroup of members willing to take on the high costs of organising such punitive mechanisms (Leonard 2000).

Co-productive arrangements for the provision of local public goods are likely to be prevalent in Sierra Leone due to weak council capacity to provide goods independently (Joshi and Moore 2004). They deserve greater recognition by local councils, the central government and donors as a model of public goods provision with the potential to deliver reasonably good outcomes even under constrained circumstances. Joshi and Moore (2004) argue that co-productive arrangements are ignored because the conceptual language to describe them has not yet been popularised within development policy discourse. In the context of the decentralisation process in Sierra Leone, co-productive arrangements are further obscured by donor assumptions that the main challenges facing local councils are ones of technical capacity and access to funding, and that local associations can best contribute to improved public goods provision by monitoring local councils' efforts, rather than co-producing goods (World Bank 2009a,b). My analysis suggests that a more empirically grounded strategy for supporting local councils is needed, which recognises that councils are fundamentally political actors whose motives are likely to be power-seeking and whose success in public goods provision is highly context-dependent. Such a strategy would pay greater attention to existing local institutions that could help councils achieve the enormous challenges with which they are tasked. 


\section{Notes}

* PhD candidate at the London School of Economics and Political Science (amworkman@gmail.com).Support for fieldwork was provided by the Africa Power and Politics Programme, Enhancing the Interaction and Interface Between the Civil Society and the State to Improve Poor People's Lives (ENCISS), the London School of Economics and Political Science, and the University of London Central Research Fund. Research assistance was provided by Emmanuel Morlai Conteh, Edward Kanu and Augusta Koroma, among others. I thank David Booth, Diana Cammack, Richard Crook, Jude Howell and Tim Kelsall for their comments on earlier drafts of this article. All errors are my own.

1 The classic economic definition of public goods holds that public goods are nonexcludable (once produced, nobody can be excluded from their benefits) and nonrivalrous (one person's enjoyment doesn't diminish another's). In practice, few goods meet these criteria when strictly applied, and in this research, public goods are taken to include the somewhat broader set of goods and services with strong positive social externalities which are underproduced because of information imperfections and thus frequently supplied by government (see Booth's Introduction, this IDS Bulletin).

2 I collected data about these two cases between January and October 2009. I use the present tense to describe the status quo at that time.

3 Prior to Makeni's upgrade to city status in 2006, Makeni City Council was known as Makeni Town Council. For simplicity's sake, I use the acronym MCC throughout to refer to all incarnations of the post-reform council.

4 I use the term 'interest-based association' to describe associations that bring together members who play similar occupational roles and enable collective action in their common interest.

5 Free-riding describes the action of benefiting from the contributions of others without making a similar contribution.

6 I used MCG's recently revised property register as the sampling frame for the survey. I drew a simple random sample of properties from this frame. I then randomly allocated properties as sites for either male or female interviews. At each property, the interviewer completed a full listing of households resident there. S/he then identified a senior representative of every household resident at the property using a standard set of criteria and interviewed him/her.

7 All currency conversions are made using an average rate for 2009 of Le $1=£ 0.00019$. Larger sums are rounded up to an appropriate unit.

8 The slaughterhouse was constructed with funds from a Local Government Development Grant, which are intended to support development projects designed by local councils in consultation with their constituents. In 2004, the first ever round of these grants, councils were required to use the grant money for projects that could be completed within 100 days, in order to build immediate trust in their capacity to deliver public goods (Kanu 2009).

9 I obtained an unofficial electronic copy of this document from MCG.

$10 \mathrm{I}$ use this term to refer to funds from central government or from donor agencies.

11 This figure was obtained from a dataset compiled by the World Bank's Institutional Reform and Capacity Building Project.

12 The position of 'chairman' was renamed 'mayor' in 2006, following Makeni's upgrade to city status.

13 The SLPP lost the election in March 1967, but a series of coups and counter-coups took place before the APC finally took office in April 1968.

14 From a local perspective, those actors most involved in directly overseeing local councils include the Decentralization Secretariat and the provincial offices within the Ministry of Internal Affairs, Local Government and Rural Development and the Local Government Finance Department within the Ministry of Finance and Economic Development.

15 The current phase of World Bank support for local councils (2009-11) includes performance bonuses for those councils who meet mutually agreed service delivery targets (World Bank 2009b). This phase of support began after my fieldwork was completed, so I do not have any information about how this measure is being implemented, or its effects. 


\section{References}

Anonymous (2006a) 'Corruption: Ultimatum for Makeni Town Chairman', Awoko, 31 January

Anonymous (2006b) 'I Resigned Because of Peace', Awoko, 16 February

Anonymous (2006c) 'Makeni Town Council Chairman to Resign Within 24 Hours', Awoko

Bolten, C.E. (2008) 'The Place is so Backward': Durable Morality and Creative Development in Northern Sierra Leone', unpublished DPhil. thesis, University of Michigan, Ann Arbor, MI

Government of Sierra Leone (2008) Second Poverty Reduction Strategy Paper (PRSP II) 2008-2012: An Agenda for Change, Freetown: Government of Sierra Leone

Greif, A. (2006) Institutions and the Path to the Modern Economy: Lessons from Medieval Trade, Cambridge, New York: Cambridge University Press

Hanlon, J. (2005) Is the International Community Helping to Recreate the Pre-Conditions for War in Sierra Leone?, Helsinki: UNU World Institute for Development Economics Research

Jalloh, A. (1999) African Entrepreneurship: Muslim Fula Merchants in Sierra Leone, Athens, $\mathrm{OH}$ : Ohio University Center for International Studies

Joshi, A. and Moore, M. (2004) 'Institutionalized Co-production: Unorthodox Public Service Delivery in Challenging Environments', Journal of Development Studies 40.4: 31-49

Kanu, A. (2009) 'Administrative Decentralization: Building the Non-Financial Capacity of Local Governments', in Y. Zhou (ed.), Decentralization, Democracy and Development: Recent Experience from Sierra Leone, Washington DC: World Bank

Leonard, D. (2000) 'The New Institutional
Economics and the Restructuring of Animal Health Services in Africa', in D. Leonard (ed.), Africa's Changing Markets for Health and Veterinary Services: The New Institutional Issues, New York: Macmillan Press

Molm, L.D.; Schaefer, D.R. and Collett, J.L. (2007) 'The Value of Reciprocity', Social Psychology Quarterly 70.2: 199-217

Ostrom, E. (2005) Understanding Institutional Diversity, Princeton, NJ: Princeton University Press

Richards, P. (2005) 'To Fight or to Farm? Agrarian Dimensions of the Mano River Conflicts (Liberia and Sierra Leone)', African Affairs 104.417: 571-90

Sierra Leone Truth and Reconciliation Commission (2004) Witness to Truth: Report of the Sierra Leone Truth and Reconciliation Commission, Accra: GPL Press

Statistics Sierra Leone (2004) Final Results: 2004 Population and Housing Census, Freetown: Statistics Sierra Leone

UNDP (United Nations Development Programme) (2009) Sierra Leone: The Human Development Index, Going Beyond Income, http://hdrstats.undp.org/en/countries/ country_fact_sheets/cty_fs_SLE.html (accessed 12 November 2010)

World Bank (2009a) Project Appraisal Document on a Proposed Credit in the Amount of SDR 12.9 Million (US\$20.0 Million Equivalent) to the Republic of Sierra Leone for the Decentralized Service Delivery Adaptable Program Loan (APL) Project in Support of the First Phase of the Decentralized Service Delivery Program, Washington DC: World Bank

World Bank (2009b) Sierra Leone Decentralized Service Delivery Program: Project Information Document Appraisal Stage, Washington DC: World Bank 